\title{
The effect of black tea on human cognitive performance in a cognitive test battery
}

\author{
Ashfique Rizwan ${ }^{1}$, Artyom Zinchenko ${ }^{2}$, Ceyona Özdem ${ }^{3}$, Md. Sohel Rana ${ }^{1}$ and Md. Mamun Al-Amin ${ }^{*}$
}

\begin{abstract}
Background: Black Tea is a widely consumed drink in the world. Evidence suggest Black Tea has stimulatory effect on humans. We investigated the effect of Black Tea on cognition using a cognitive test battery.

Methods: Participants $(n=32)$ were fasted overnight for $10 \mathrm{~h}$ and restrained from caffeine and other stimulant drugs for 14 days prior to participation. We randomly assigned participants into either an experimental $(n=16)$ or a control $(n=16)$ group. Experimental group consumed $250 \mathrm{ml}$ of Black Tea (BT) while control group was received equal volume of water (W). Participants were tested on the following cognitive tasks: executive function, sustained attention, memory (memory span, immediate, delayed, working memory) and arithmetic calculation task.

Results: We found that BT group performed significantly $(p<0.05)$ faster in the executive function task (BT: $M=1671$, $S D=319 ; W: M=1935, S D=372)$; simple reaction time task ( $B T: M=333, S D=87 ; W: M=361, S D=101$ ), identification of target location in the visual search task (BT: $M=925, S D=50 ; W: M=972, S D=115)$. We also showed that BT group forgotten significantly $(p<0.05)$ lower number of words in the delayed memory recall test (BT: $M=1.12, S D=0.15 ; W$ : $M=1.37, S D=0.33)$ and made significantly $(p<0.05)$ fewer errors in the trail making task $(B T: M=0.31, S D=1.01$; $W: M=1.31, S D=1.66)$.

Conclusions: BT consumption speeded the performance, improved memory, reduced number of errors in the various cognitive tasks. Our results further showed that even in small volume of BT consumption can speed up cognitive processing.
\end{abstract}

Keywords: Attention, Memory, Reaction time, Cognition, Visual search

\section{Background}

Tea is the second most extensively consumed beverages on the planet [1]. The popularity of tea could possibly be explained by its pharmacological action. For instance, the component of tea such as caffeine increases cortisol level in response to stress [2]. Drinking tea produced stimulation which further helps to overcome psychosocial stress [3], enhances cognitive performance [4] and improves attention [5]. Tea contains phenolic compounds that facilitates synaptic plasticity [6]. The principle constituents of black tea are caffeine and Ltheanine. The amount of caffeine and L-theanine in one cup of tea varies. It is estimated that, $200 \mathrm{ml}$ of black tea contain 35-61 mg of caffeine and 4.5-22.5 mg of L-

\footnotetext{
* Correspondence: mamun.al-amin@northsouth.edu; bd_pharmacy@yahoo.com; mdalaminbadal@gmail.com

${ }^{4}$ Department of Pharmaceutical Sciences, North South University, Plot-15, Block-B, Bashundhara, Dhaka 1229, Bangladesh

Full list of author information is available at the end of the article
}

theanine. Caffeine is quickly absorbed (30-40 min, halflife $=3$ to 6 h) [7]. Importantly, the effect of caffeine on cognitive function is not limited to a particular type of tea [8].

Previous studies investigated the effects of caffeine and L-theanine on human cognitive performances and behavior. The effect of caffeine and L-theanine on cognition are summarized in Table 1. Higher consumption of tea is associated with a lower risk of cognitive impairment [9]. In elderly people ( $>60$ years old), Black tea consumption improves cognitive performances [10]. Importantly, caffeine improves sustained attention [5], mood and reduces fatigue [11-13], improves motor-skill performance in tasks such as a simulated driving task [14] and improves handwriting [15]. Caffeine at a dose of 200-250 mg improves attention in visual search task [16]. Functional magnetic resonance imaging (fMRI) study reported that caffeine alters neuronal activity in 
Table 1 Summary of published findings on the effect of Black Tea on cognitive process

\begin{tabular}{|c|c|c|c|c|}
\hline Study & Dose & Task type & Positive effect & Negative or No effect \\
\hline $\begin{array}{l}\text { Caffeine, ERP } \\
\text { study [29] }\end{array}$ & $250 \mathrm{mg}$ & Auditory Go/NoGo & $\begin{array}{l}\text { Global increases in P1, P2 and P3b } \\
\text { amplitudes to Go stimuli }\end{array}$ & $\begin{array}{l}\text { N1 or N2 (Go stimuli), any } \\
\text { components (NoGo stimuli) }\end{array}$ \\
\hline $\begin{array}{l}\text { Caffeine, ERP } \\
\text { study [16] }\end{array}$ & $3 \mathrm{mg} / \mathrm{kg}$ & Visual search & Subjects reacted faster & $\begin{array}{l}\text { Negative ERP deflection } \\
\text { was unaffected }\end{array}$ \\
\hline Caffeine [20] & $400 \mathrm{mg}$ & $\begin{array}{l}\text { Visual search, Simple choice } \\
\text { reaction time }\end{array}$ & $\begin{array}{l}\text { Positive effect depends on the level } \\
\text { of caffeine use. }\end{array}$ & \\
\hline Green tea [9] & 1 cup to 6 cups & Mini-Mental State Examination & $\begin{array}{l}\text { Higher consumption is associated } \\
\text { with a lower prevalence of } \\
\text { cognitive impairment }\end{array}$ & \\
\hline $\begin{array}{l}\text { Breakfast cereal } \\
\text { and caffeinated } \\
\text { coffee [22] }\end{array}$ & & $\begin{array}{l}\text { Working memory, attention } \\
\text { and mood }\end{array}$ & & $\begin{array}{l}\text { No effect on initial mood or } \\
\text { working memory capacity }\end{array}$ \\
\hline Caffeine [21] & & Visual information processing & & $\begin{array}{l}\text { Does not affect cognition, } \\
\text { learning \& memory } \\
\text { performance }\end{array}$ \\
\hline $\begin{array}{l}\text { Breakfast and } \\
\text { caffeine [50] }\end{array}$ & $4 \mathrm{mg} / \mathrm{kg}$ & $\begin{array}{l}\text { Free recall and recognition } \\
\text { memory and semantic } \\
\text { memory }\end{array}$ & & Impaired accuracy \\
\hline $\begin{array}{l}\text { Glucose \& caffeine, } \\
\text { fMRI study [53] }\end{array}$ & $\begin{array}{l}\text { Glucose }(75 \mathrm{~g})+ \\
\text { Caffeine }(75 \mathrm{~g})\end{array}$ & Sustained attention & $\begin{array}{l}\text { Increase the efficiency of the } \\
\text { attentional system }\end{array}$ & \\
\hline Caffeine [25] & $4 \mathrm{mg} / \mathrm{kg}$ & $\begin{array}{l}\text { Delayed memory, } \\
\text { metamemory and sustained } \\
\text { attention }\end{array}$ & & $\begin{array}{l}\text { Not affect the magnitude or } \\
\text { accuracy of memory } \\
\text { predictions }\end{array}$ \\
\hline $\begin{array}{l}\text { Caffeine, fMRI } \\
\text { study [54] }\end{array}$ & $100 \mathrm{mg}$ & WM maintenance task & & $\begin{array}{l}\text { Detrimental effect on WM at } \\
\text { higher levels of WM load }\end{array}$ \\
\hline $\begin{array}{l}\text { Caffeine, fMRI } \\
\text { study[17] }\end{array}$ & 250 or $500 \mathrm{ml}$ & WM & Alters brain activity in DLPFC area & \\
\hline Caffeine [55] & 200 mg & 'N-Back' WM paradigm & Heightened WM performance & \\
\hline $\begin{array}{l}\text { Caffeine, Review } \\
\text { paper [56] }\end{array}$ & & & & $\begin{array}{l}\text { Does not improve learning } \\
\text { and memory }\end{array}$ \\
\hline $\begin{array}{l}\text { L-theanine, } \\
\text { caffeine [26] }\end{array}$ & $\begin{array}{l}\text { L-theanine }(250 \mathrm{mg})+ \\
\text { caffeine }(150 \mathrm{mg})\end{array}$ & $\begin{array}{l}\text { Simple reaction time, } \\
\text { Numeric WM RT and } \\
\text { sentence verification }\end{array}$ & $\begin{array}{l}\text { Faster reaction time and improved } \\
\text { sentence verification accuracy }\end{array}$ & \\
\hline $\begin{array}{l}\text { L-theanine, } \\
\text { caffeine [28] }\end{array}$ & $\begin{array}{l}\text { L-theanine } \\
\text { (100 mg) }\end{array}$ & Target discrimination & $\begin{array}{l}\text { Increase in hit rate and target } \\
\text { discriminability }\left(d^{\prime}\right) \text { for the } \\
\text { combined treatment }\end{array}$ & $\begin{array}{l}\text { No effects were detected for } \\
\text { I-theanine alone }\end{array}$ \\
\hline L-theanine [27] & $\begin{array}{l}200 \mathrm{mg}+100 \mathrm{ml} \\
\text { water }\end{array}$ & Attention test & $\begin{array}{l}\text { Improves attention and reaction } \\
\text { time response }\end{array}$ & \\
\hline
\end{tabular}

the DLPFC (dorsolateral Pre-Frontal Cortex) on working memory task [17]. Caffeine also modulates neuronal activity [18]. Caffeine improves low alertness during long drive [14]. Besides caffeine, Theanine improves attentional performance at a dose of $200 \mathrm{mg} / 100 \mathrm{ml}$ water [19]. Important to notice, effect of caffeine is shown to be related to the habitual intake levels. It has been reported that higher caffeine consumers are more likely to perceive broadly positive effects of caffeine [20].

Surprisingly, caffeine does not always produces beneficial effects, especially at less than $100 \mathrm{mg}$ dose. Caffeine does not affect cognition and memory performance, learning and initial mood [21, 22], long- and short term memory in a delayed recall verbal memory task [23, 24], and complex short-term memory task performance [4].

\section{Aim of the study}

We selected Black Tea (BT) since the principle constituent of black tea are two stimulating agents, namely caffeine and L-theanine. It is generally believed that caffeine containing black tea improves human cognitive functioning. However, previous studies reported inconsistent results. These studies used different tasks $[25,26]$, varied the dosage of caffeine and L-theanine in the tea [26-28], tested participants in different cognitive tasks $[8,20,29,30]$. Therefore, we aimed to identify the influence of BT consumption on human cognitive functioning, testing the participants in a wide range of cognitive tasks with a low dose that is $50 \mathrm{mg}$ and $15 \mathrm{mg}$ respectively. This small dose have shown no effect on cognitive functioning due to the habitual 
intake level [20]. In this study, we controlled habitual black tea consumption level of each participants' prior to the experiment (i.e., consumption of tea was completely restricted for 2 weeks prior to experiment). Moreover, previous studies used relatively simple tasks [14, 30-32] (although see [4] for a more complicated task). Therefore, we used relatively complex test procedures such as trail making tests [33], card sorting test [34, 35], calculation tasks etc.

We hypothesized that BT at a low dose [caffeine (50 $\mathrm{mg}$ ) and plus L-theanine (15 mg)] would enhance cognitive performance. This enhancement could be due to the faster bioavailablity of caffeine to the brain which is $40 \mathrm{~min}$ following drinking [36]. Although cerebral blood circulation may affect cognitive performance, affecting several brain regions at the same time. Therefore, the consumption of BT was expected to influence cognitive processes during the series of behavioural tasks in the cognitive test battery (PEBL) [37].

\section{Methods}

\section{Participants}

Thirty two healthy volunteers (12 female; mean age $=21$ ) took part in this study. Participants were recruited and controlled for the level of IQ measured by the National Adult Reading Test (mean IQ = 110.62); [38] and were naive to the purpose of experiment. Participants fasted for $10 \mathrm{~h}$ overnight and restrained themselves from consumption of tea, caffeine or other stimulant drinks and drugs for 14 days prior to participation in the experiment. All participants had normal or corrected to normal vision.

\section{Procedure}

Participants were instructed to sleep at least $8 \mathrm{~h}$ overnight and came at 6.30 AM to the test center (Department of Pharmacy, Jahangirnagar University, Savar, Dhaka, Bangladesh). Participants were divided into two groups; (i) experimental group consumed $250 \mathrm{ml}$ of Black Tea (BT) $40 \mathrm{~min}$ before testing, assuming caffeine at a dose of $50 \mathrm{mg}$ plus L-theanine at a dose of $15 \mathrm{mg}$ while (ii) control group consumed $250 \mathrm{ml}$ of water (i.e., drinking water; not boiled or distilled). Subjects were randomized to participate in this experiment. A person blind to the purpose of the experiment was involved in assigning subjects for each condition. Before starting the cognitive test battery, participants were shown the procedures for attending the battery of test by a projector as a training phase.

\section{Preparation of drink}

BT was purchased from Kazi and Kazi tea, Dhaka, Bangladesh and added to $250 \mathrm{ml}$ of drinking water.

\section{Immediate recall memory test}

A list of 10 words was presented to the subjects at a rate of one every 2 second. At the end of the presentation, subjects were given $1 \mathrm{~min}$ to write down as many words as possible.

\section{Delayed recall memory test}

At the end of the test session (average 90 min test session) subjects were given $1 \mathrm{~min}$ to recall as many words as possible from the list shown at the beginning of the study. The number of words forgotten was calculated by subtracting number of words reproduced correctly from the total number of words presented to participants. The difference between numbers of words remembered in the learning trial versus the delayed recall was obtained as an estimation of forgetting.

\section{Trail making test $A$ and $B$}

Participants were asked to connect circles in a specified sequence using pencil to draw lines as rapidly as possible. Condition A involved sequence for connecting the circles in a numeric sequence. Condition B involved circles with alternating numeric and alphabetic sequences.

The psychology experiment building language (PEBL) Version 0.13 [37] was used to test the performance of Visual search, Berger's card sorting test, Memory span, Sustained attention and Arithmetic calculation.

\section{Visual search task}

Participants were asked to find the target (odd colored " $\mathrm{X}$ " or "O") in a randomly displayed stimulus in the screen. In some trials the target was present and in other trials it was absent. Participants responded with left click of the mouse button. Following the mouse click, the targets were replaced by a mask. Participants were instructed to 'click' on the location of the target. If the target was absent on the screen, following the mouse click, the instruction was to 'click' on the 'none' button. Each participant completed 180 trials.

\section{Berg's Card Sorting Test (BCST)}

This is a computerized version of wisconsin card sorting test $[39,40]$. Each participant had to complete 128 trials. BCST [41] assessed performance in various tasks: cognitive processing speed, concept formation, inhibition capacity and cognitive flexibility.

\section{Simple reaction time task}

Participants were asked to press the space button as quickly as possible every time the red 'dot' was presented on the monitor in 121 trials for the PPVT (PEBL Perceptual Vigilance Task) program of PEBL. The stimuli were presented with an inter-stimulus interval that 
varied randomly between 1 and 3.5 seconds. Reaction Times (RTs) were recorded in milliseconds.

\section{Memory span test}

This test was used to measure the ability to remember a sequence of locations. In each of the trials nine blue squares were displayed on the screen and these squares lit up one at a time in different sequences. Participants were required to observe the sequence and memorize the order in which the squares lit up. After each trial, subjects were asked to replicate the sequence by clicking on corresponding squares in the right order.

\section{Arithmetic calculation test}

It was used to examine the ability to solve a number of simple addition and subtraction problems. Participants were asked to determine whether the answer of each arithmetic operation is greater or less than 5 . Each testing block is $3 \mathrm{~min}$ long. In separate blocks the task of participants was to do one, two and three digit addition/ subtraction operations, with equal number of trials in each block. Participants were asked to perform the task as quickly and accurately as possible.

\section{Apparatus}

Stimuli were presented on 15" CRT (Cathode Ray Tube) screen monitor (SAMSUNG Syncmaster 794MG, made in Malaysia) with a $100 \mathrm{~Hz}$ refresh rate placed at a distance of $100 \mathrm{~cm}$ from an observer. Responses were gathered with a Logitech optical mouse (Made by Logitech Inc. in China). The whole experiment was programmed in PEBL software run on an Intel ${ }^{\circledR}$ Core $^{\text {тм }} 2$ CPU 6700 @ $2.66 \mathrm{Ghz}, 2 \mathrm{CPUs}$ ) computer with Microsoft Windows XP Professional operating system.

\section{Data analysis}

Repeated measures ANOVA was used to check for effects of BT on cognitive performance in visual search and arithmetic calculation tasks. Independent sample ttest was conducted to analyze the results of simple reaction time, BCST, memory span, immediate/delayed recall memory and verbal fluency tests. In independent sample t-test, BT and water were grouping variables and all reaction time and other interval data were dependent variable. Reaction times above $1500 \mathrm{~ms}$ (too slow) or below $50 \mathrm{~ms}$ (too fast) were excluded during the data analysis of visual search, sustained attention, simple reaction time task. In case of BCST and "mathproc" test the upper cut off value for RT was $300 \mathrm{~ms}$ and lowest value was $50 \mathrm{~ms}$ since they are complicated task and participants required more time than comparatively other tasks. Moreover mean \pm 2 S.D. was used to exclude odd data. All analyses were carried out with the SPSS package (version 16.0). The difference was considered significant when $p$ value was less than 0.05. Data were represented as mean \pm SD (Standard Deviation).

\section{Results \\ Demographic information}

There was no difference in between control and experimental conditions in terms of age $(21.5 \pm 1.26$ vs 20.88 $\pm 0.71)$ and IQ level $(106.29 \pm 23.34$ vs $100.71 \pm 31.22)$ (Table 2).

\section{Immediate and delayed recall memory test}

Independent samples t-test was conducted to compare the average number of words forgotten in the delayed recall test between BT and W group. There was a significant difference $(p<0.05)$ between the BT $(\mathrm{M}=1.12$, $\mathrm{SD}=0.15)$ and $\mathrm{W}$ condition $(\mathrm{M}=1.37, \mathrm{SD}=0.33)$; $\mathrm{t}(30)=1.89, p<0.05$. Participants in $\mathrm{W}$ group forgot more words than BT group (Fig. 1).

\section{Trail making test $A$ and $B$}

Independent samples t-test revealed no significant difference $(p<0.01)$ between BT and W groups. MannWhitney test was used due to the fact that values of standard deviations (SD) were larger than the mean in each of the groups. Error rates in trail making test A were significantly lower in $\mathrm{BT}(\mathrm{M}=0.31 ; \mathrm{SD}=1.01)$ than water $(\mathrm{M}=1.31 ; \mathrm{SD}=1.66)$. Moreover, participants with BT made less error $(p<0.01)$.

\section{Visual search task}

Independent samples t-test was conducted to compare the Reaction Time for identifying the target between BT and $\mathrm{W}$ group. There was no difference in the RT between BT $(\mathrm{M}=984, \mathrm{SD}=109)$ and $\mathrm{W} \quad(\mathrm{M}=999, \mathrm{SD}=101)$ groups $\mathrm{t}(30)=-0.38, p>0.05$.

Independent samples t-test was conducted to compare the Reaction Time (RT) for identifying the location of the target between $\mathrm{BT}$ and $\mathrm{W}$ group. We found a significant difference in the RTs between BT $(M=925$, $\mathrm{SD}=50)$ and $\mathrm{W}(\mathrm{M}=972, \mathrm{SD}=115)$ condition; $\mathrm{t}(0.28)$ $=-1.07, p<0.05$. Repeated measures ANOVA showed the main effect of stimulus size: a gradual increase in RTs with increase in set size for both groups $\mathrm{F}(2,14)=$ 5.6, $p<0.05$ (Fig. 2).

\section{Berger's card sorting test}

We found no difference between the BT $(\mathrm{M}=8.81 \%$, $\mathrm{SD}=5.74)$ and $\mathrm{W}(\mathrm{M}=9.38 \%, \mathrm{SD}=5.99)$ groups in the error rates; $\mathrm{t}(30)=-0.271, p>0.5)$. In other words, both groups made comparable number of errors in the test. However, there was a difference in RTs. BT group $(\mathrm{M}=1671, \mathrm{SD}=319)$ was faster relative to the $\mathrm{W}(\mathrm{M}$ $=1935, \mathrm{SD}=372$ ) group; $\mathrm{t}(30)=-2.155, p<0.05)$, although participants were not instructed to give a 
Table 2 Demographic data and participant's performance in various cognitive tasks in PEBL test battery

\begin{tabular}{|c|c|c|c|c|}
\hline & & Black Tea (BT) & Water (W) & $P$ value \\
\hline Age & Year & $21.5 \pm 1.26$ & $20.88 \pm 0.71$ & $>0.1$ \\
\hline IQ level & & $106.29 \pm 23.34$ & $100.71 \pm 31.22$ & $>0.1$ \\
\hline Memory Span & Average block & $5.31 \pm 0.89$ & $4.90 \pm 0.84$ & $>0.1$ \\
\hline Immediate Recall Memory Test & No. of words retrieved & $8.06 \pm 0.32$ & $7.75 \pm 0.22$ & $>0.1$ \\
\hline \multirow[t]{2}{*}{ Delayed Recall Memory Test } & No. of words retrieved & $7.56 \pm 0.93$ & $6.50 \pm 0.37$ & $>0.1$ \\
\hline & No. of words failed to recall & $1.12 \pm 0.15$ & $1.37 \pm 0.32$ & $<0.05$ \\
\hline \multirow[t]{2}{*}{ Berger's Card Sorting Test } & Persev_error & $8.81 \pm 5.74$ & $9.38 \pm 5.99$ & $>0.1$ \\
\hline & $\mathrm{RT}(\mathrm{ms})$ & $1671 \pm 319$ & $1935 \pm 372$ & $<0.05$ \\
\hline Simple Reaction Time Task to measure Sustained Attention & $\mathrm{RT}(\mathrm{ms})$ & $333 \pm 2$ & $361 \pm 2$ & $<0.05$ \\
\hline Visual Search (Target identification) & $\mathrm{RT}$ (ms) & $984 \pm 32$ & $999 \pm 37$ & $>0.1$ \\
\hline Visual Search (Target location) & $\mathrm{RT}$ (ms) & $925 \pm 12$ & $972 \pm 28$ & $<0.05$ \\
\hline
\end{tabular}

Total subjects $(n=32)$; water $(n=16)$; Black Tea $(n=16)$; RT Reaction Time; Data were represented as Mean \pm SEM; RTs were shown in millisecond (ms

speeded response. This may suggest that BT consumption could facilitate RTs in BCST task.

\section{Simple reaction time task}

Independent samples t-test was conducted to compare the Reaction Time in the sustained attention task between $\mathrm{BT}$ and $\mathrm{W}$ group. We found a significant difference in the $\mathrm{RT}$ for $\mathrm{BT}$ condition $(\mathrm{M}=333, \mathrm{SD}=87)$ and $\mathrm{W}$ condition $(\mathrm{M}=361, \mathrm{SD}=101)$; $\mathrm{t}(30)=-8.43, p<0.05$.

\section{Memory span test}

We showed no difference in the memory for BT $(\mathrm{M}=5.31$, $\mathrm{SD}=0.89)$ and $\mathrm{W}$ conditions $(\mathrm{M}=4.90, \mathrm{SD}=0.84)$; $\mathrm{t}(30)=-1.32, p>0.05$ following independent sample $\mathrm{t}-$ test analysis.

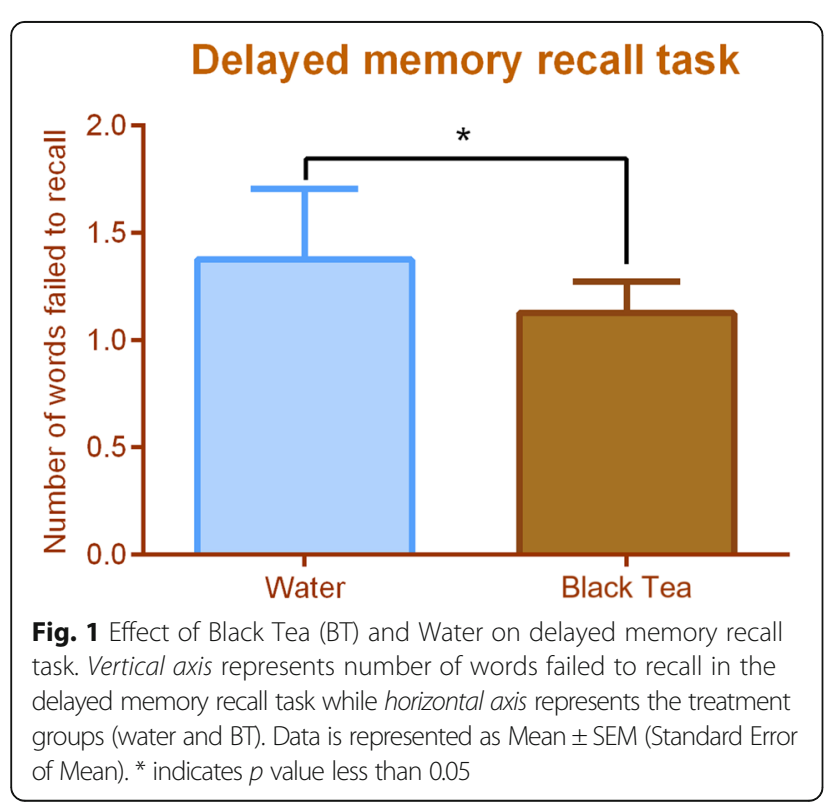

\section{Arithmetic calculation test}

Repeated measure ANOVA revealed no effect of BT on neither speed nor accuracy of arithmetic calculations task F $2,14=6.4, p>0.05$.

\section{Discussion}

We investigated the influence of BT on the performance of a series of cognitive tasks, controlling for the habitual intake level of caffeine, complexity of the task and interparticipant differences in cognition. We used a lower amount of BT since several studies suggeste BT does not influence certain cognitive functions [28], particularly at the dosage of less than $100 \mathrm{mg}[22,23]$. We found BT groupe sowed improved performances in a number of

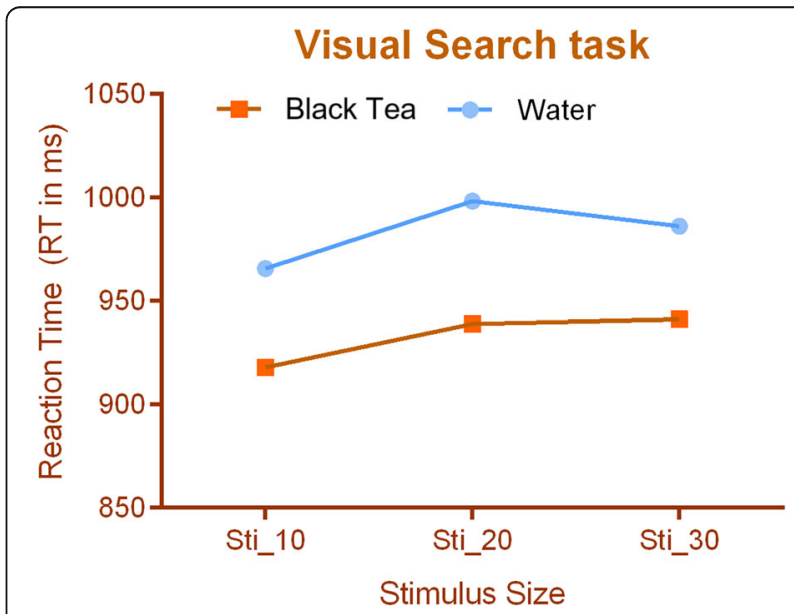

Fig. 2 Effect of Black Tea (BT) and Water on Visual Search task. Vertical axis represents Reaction Time (RT) in millisecond (ms) while represents various stimulus size namely, Sti_10: Stimulus Size 10; Sti_20: Stimulus Size 20; Sti_30: Stimulus Size 30. Data is represented as Mean value 
cognitive tasks. In line with previous results, we have also shown facilitation effect of BT on cognition [2].

We showed drinking of BT facilitated cognitive functions in delayed recall memory test. BT group forgotten fewer words. It is presumable that drinking of BT accelerates the consolidation [36] and retrieval of memory. The memory traces could be stabilized during the experimental sessions which helped BT consumers to retrieve the words [42]. A revious study [17] suggest that caffeine alters neuronal activity in the DLPFC (dorsolateral Pre-Frontal Cortex) during performance on a working memory task [38]. Additionally, our study showed that this effect might already had at caffeine dose of less than $70 \mathrm{mg}$.

Further, BT consumers were more accurate in performing trail making test $\mathrm{A}$. Trial making is a complex task that requires sustained attention, alertness, speeded motor activity to be activated at the same time. Previous studies showed a positive effect of caffeine on sustained attention [36] alertness [25] and motor activity [43] separately. Trail making test confirms our hypothesis that a merging of facilitation events might produce a combinatory effect on cognitive processing.

Another important finding of the present study is that BT consumers were faster in identifying target location in the visual search task. This effect is only possible when a combination of higher level cognition (e.g., attention, alertness, short term memory) is involved in the task. Identifying an object in their location is a hippocampal-dependent task. It is possible that BT consumers had learned better in this spatial learning task. This finding goes in line with the caffeine related improved performance in the Berg's Card Sorting Test (BCST) and simple reaction time tasks and supports previous findings that showed caffeine induced facilitation of attention [32, 44] and level of alertness [13, 45]. It is also consistent with other previous studies $[2,16$, $19,38]$ that linked consumption of tea to robust increases in alertness and information processing capacity [4]. As cholinergic mechanisms have been shown to be a necessary condition for memory formation in rats [46], we hypothesize that BT might also be able to influence the level of cholinergic mechanisms in humans, thus improving memory formation [46].

Caffeine facilitation in visual search task raises an important issue for the cognitive psychology research that greatly relies on reaction time (RT) data in visual search tasks. Since caffeine and L-theanine in tea are a regularly consumed drink by the students, it might influence behavioral results in cognitive experiments. Therefore, it could be recommended to additionally measure the level of caffeine consumption among participants of various $\mathrm{RT}$ experiments and use it as an additional factor during the statistical analysis.
Visual search task is an established neuropsychological tool for testing the iconic memory $[47,48]$. It measures two parameters: the reaction time (RT) necessary to either detect or determine spatial location of the target. Both groups (i.e., BT and W) performed equally well in the first task - target detection. However, BT group showed facilitated identification of target location, relative to the control group. To our knowledge, we first report that BT is able to improve iconic memory. There are several non-exclusive explanations of this effect. Possibly, caffeine is able to facilitate attention allocation that is necessary to locate a target [49]. On the other hand, caffeine could facilitate the decision making stage of visual search, which allowed BT participants to perform faster [20,50]. Additionally, overall stimulant effect of caffeine could possibly enhance motor processes that cause the improved performance [43]. This latter point is, however, less likely since previous studies showed no effect of caffeine on human motor functioning [51]; although see [14] for a different view. Further Electroencephalographic (EEG) experiment would be necessary to identify the stage of visual processing that is influenced by caffeine: attention allocation i.e., N2PC (N200 component of posterior contralateral) [52].

Arithmetic calculation task (ACT), memory span and iconic memory (target location identification) were for the first time tested in this experiment. We showed that BT does not affect arithmetic calculation and memory span, but enhances iconic memory.

Our study has several limitations. First, the number of participants was ( $n=16$ in each groups) relatively smaller and we used a lower volume of BT. Additionally, we measured only behavioral performance. Therefore, future studies should test larger groups of participants as well as employ Event Related Potential (ERP) methodology.

\section{Conclusions}

Tea is one of the most popular drinks because of having two stimulants, caffeine and l-theanine. Caffeine increases the level of alertness and improves cognitive functions. Previous studies showed that consumption of caffeine is able to facilitate certain cognitive processes (e.g., short term memory, simple RTs etc.). In our present study, we tested the influence of black tea on human cognitive performance in a battery of cognitive tests. We showed that BT improved the speed of attention allocation, speeded visual search and increased level of alertness. However, additional studies are required in order to identify specific stages of visual processing that are being influence by BT consumption as well as long term BT effects on human cognitive functioning. 


\section{Abbreviations}

BCST: Berg's Card Sorting Test; BT: Black Tea; PEBL: Psychology experiment building language (PEBL)

\section{Acknowledgements}

We would like to acknowledge the contribution of the LNPR (Laboratory of Natural Product Research) team, Jahangirnagar University, Dhaka, Bangladesh. We would like to give them special thanks for providing all sorts of supports towards this study.

\section{Authors' contributions}

AR and MMAA designed the study. AR collected the data. AR, AZ, CO and MMAA analyzed the data. MMAA and AR prepared the manuscript. AZ and MSR revised the manuscript. All authors read and approved the final manuscript.

\section{Competing interests}

The authors declare that they have no competing interests.

\section{Ethics approval and consent to participate}

Participants signed an informed consent form. Participants and instructors were awarded with breakfast and snacks at the post test session. Experimental protocol was approved by Institutional Review Board of the Department of Pharmacy, Jahangirnagar University (Approval No. JU/LS/Pha/ 2013/1040).

\section{Publisher's Note}

Springer Nature remains neutral with regard to jurisdictional claims in published maps and institutional affiliations.

\section{Author details}

'Department of Pharmacy, Jahangirnagar University, Savar, Dhaka 1342, Bangladesh. ${ }^{2}$ Max Planck Institute for Human Cognitive and Brain Sciences, Stephanstraße 1A, 04103 Leipzig, Germany. ${ }^{3}$ Department of Psychology, Vrije Universiteit Brussel, Pleinlaan 2, B - 1050 Brussel, Belgium. ${ }^{4}$ Department of Pharmaceutical Sciences, North South University, Plot-15, Block-B, Bashundhara, Dhaka 1229, Bangladesh.

Received: 20 October 2016 Accepted: 21 May 2017

Published online: 15 June 2017

\section{References}

1. Matthews CM. Steep your genes in health: drink tea. Proc (Baylor Univ Med Cent). 2010;23(2):142-4.

2. Lovallo WR, Farag NH, Vincent AS, Thomas TL, Wilson MF. Cortisol responses to mental stress, exercise, and meals following caffeine intake in men and women. Pharmacol Biochem Behav. 2006;83(3):441-7.

3. Unno K, Iguchi K, Tanida N, Fujitani K, Takamori N, Yamamoto H, et al. Ingestion of theanine, an amino acid in tea, suppresses psychosocial stress in mice. Exp Physiol. 2013;98(1):290-303.

4. Hindmarch I, Quinlan PT, Moore KL, Parkin C. The effects of black tea and other beverages on aspects of cognition and psychomotor performance. Psychopharmacology. 1998;139(3):230-8.

5. Smith AP, Rusted JM, Eaton-Williams P, Savory M, Leathwood P. Effects of caffeine given before and after lunch on sustained attention. Neuropsychobiology. 1990;23(3):160-3.

6. Gomez-Pinilla F, Nguyen TT. Natural mood foods: the actions of polyphenols against psychiatric and cognitive disorders. Nutr Neurosci. 2012;15(3):127-33.

7. Rogers PJ. Caffeine, mood and mental performance in everyday life. Nutr Bull. 2007;32:84-9

8. Feng L, Gwee X, Kua EH, Ng TP. Cognitive function and tea consumption in community dwelling older Chinese in Singapore. J Nutr Health Aging. 2010;14(6):433-8.

9. Kuriyama S, Hozawa A, Ohmori K, Shimazu T, Matsui T, Ebihara S, et al. Green tea consumption and cognitive function: a cross-sectional study from the Tsurugaya Project 1. Am J Clin Nutr. 2006;83(2):355-61.

10. Shen $W$, Xiao $Y$, Ying $X$, Li S, Zhai $Y$, Shang $X$, et al. Tea consumption and cognitive impairment: a cross-sectional study among Chinese elderly. PLoS ONE. 2015;10(9):e0137781.

11. Winston AP, Hardwick $E$, Jaberi N. Neuropsychiatric effects of caffeine. Adv Psychiatr Treat. 2005;11(6):432-9.
12. Rogers PJ, Dernoncourt C. Regular caffeine consumption: a balance of adverse and beneficial effects for mood and psychomotor performance. Pharmacol Biochem Behav. 1998;59(4):1039-45.

13. Smith A. Effects of caffeine on human behavior. Food Chem Toxicol. 2002;40(9):1243-55.

14. Brice C, Smith A. The effects of caffeine on simulated driving, subjective alertness and sustained attention. Hum Psychopharmacol. 2001;16(7):523-31.

15. Tucha O, Walitza S, Mecklinger L, Stasik D, Sontag TA, Lange KW. The effect of caffeine on handwriting movements in skilled writers. Hum Mov Sci. 2006;25(4-5):523-35.

16. Lorist MM, Snel J, Kok A, Mulder G. Acute effects of caffeine on selective attention and visual search processes. Psychophysiology. 1996;33(4):354-61.

17. Borgwardt S, Hammann F, Scheffler K, Kreuter M, Drewe J, Beglinger C. Neural effects of green tea extract on dorsolateral prefrontal cortex. Eur J Clin Nutr. 2012;66(11):1187-92.

18. Koppelstaetter F, Poeppel TD, Siedentopf CM, Ischebeck A, Verius M, Haala I, et al. Does caffeine modulate verbal working memory processes? An fMRI study. Neurolmage. 2008;39(1):492-9.

19. Higashiyama A, Htay HH, Ozeki M, Juneja LR, Kapoor MP. Effects of I-theanine on attention and reaction time response. J Funct Foods. 2011;3(3):171-8.

20. Attwood AS, Higgs S, Terry P. Differential responsiveness to caffeine and perceived effects of caffeine in moderate and high regular caffeine consumers. Psychopharmacology. 2007;190(4):469-77.

21. Loke $W H$. The effects of caffeine and automaticity on a visual information processing task. Hum Psychopharmacol Clin Exp. 1992;7(6):379-88.

22. Smith AP, Clark R, Gallagher J. Breakfast cereal and caffeinated coffee: effects on working memory, attention, mood, and cardiovascular function. Physiol Behav. 1999;67(1):9-17.

23. Herz RS. Caffeine effects on mood and memory. Behav Res Ther 1999;37(9):869-79.

24. Warburton DM, Bersellini E, Sweeney E. An evaluation of a caffeinated taurine drink on mood, memory and information processing in healthy volunteers without caffeine abstinence. Psychopharmacology. 2001;158(3):322-8.

25. Kelemen $\mathrm{WL}$, Creeley CE. Caffeine ( $4 \mathrm{mg} / \mathrm{kg}$ ) influences sustained attention and delayed free recall but not memory predictions. Hum Psychopharmacol. 2001:16(4):309-19.

26. Haskell CF, Kennedy DO, Milne AL, Wesnes KA, Scholey AB. The effects of I-theanine, caffeine and their combination on cognition and mood. Biol Psychol. 2008;77(2):113-22.

27. Lu K, Gray MA, Oliver C, Liley DT, Harrison BJ, Bartholomeusz CF, et al. The acute effects of L-theanine in comparison with alprazolam on anticipatory anxiety in humans. Hum Psychopharmacol. 2004;19(7):457-65.

28. Kelly SP, Gomez-Ramirez M, Montesi JL, Foxe JJ. L-theanine and caffeine in combination affect human cognition as evidenced by oscillatory alphaband activity and attention task performance. J Nutr. 2008;138(8):1572S-7.

29. Barry RJ, Johnstone SJ, Clarke AR, Rushby JA, Brown CR, McKenzie DN. Caffeine effects on ERPs and performance in an auditory Go/NoGo task. Clin Neurophysiol. 2007;118(12):2692-9.

30. Steptoe A, Gibson EL, Vuononvirta R, Williams ED, Hamer M, Rycroft JA, et al. The effects of tea on psychophysiological stress responsivity and post-stress recovery: a randomised double-blind trial. Psychopharmacology. 2007;190(1):81-9.

31. Carolyn MM. Steep your genes in health: drink tea. Proc (Bayl Univ Med Cent). 2010:23(2):142-4.

32. Henning SM, Niu Y, Lee NH, Thames GD, Minutti RR, Wang $H$, et al. Bioavailability and antioxidant activity of tea flavanols after consumption of green tea, black tea, or a green tea extract supplement. Am J Clin Nutr. 2004;80(6):1558-64.

33. Arbuthnott K, Frank J. Trail making test, part B as a measure of executive control: validation using a set-switching paradigm. J Clin Exp Neuropsychol. 2000;22(4):518-28.

34. Koren D, Seidman $\sqcup$, Harrison RH, Lyons MJ, Kremen WS, Caplan B, et al. Factor structure of the Wisconsin Card Sorting Test: dimensions of deficit in schizophrenia. Neuropsychology. 1998;12(2):289-302.

35. Gold JM, Carpenter C, Randolph C, Goldberg TE, Weinberger DR. Auditory working memory and Wisconsin Card Sorting Test performance in schizophrenia. Arch Gen Psychiatry. 1997:54(2):159-65.

36. Dixit A, Vaney N, Tandon OP. Evaluation of cognitive brain functions in caffeine users: a P3 evoked potential study. Indian J Physiol Pharmacol. 2006;50(2):175-80 
37. Mueller ST, Piper BJ. The Psychology Experiment Building Language (PEBL) and PEBL test battery. J Neurosci Methods. 2014;222:250-9.

38. Nelson H, Willison J. National Adult Reading Test (NART). nferNelson; 1991. https://egret.psychol.cam.ac.uk/camcops/documentation/tasks/nart.html.

39. Demakis GJ. A meta-analytic review of the sensitivity of the Wisconsin Card Sorting Test to frontal and lateralized frontal brain damage. Neuropsychology. 2003;17(2):255-64.

40. Piper BJ, Li V, Eiwaz MA, Kobel YV, Benice TS, Chu AM, et al. Executive function on the Psychology Experiment Building Language tests. Behav Res Methods. 2012:44(1):110-23.

41. Fox CJ, Mueller ST, Gray HM, Raber J, Piper BJ. Evaluation of a short-form of the Berg Card Sorting Test. PLoS One. 2013;8(5):e63885.

42. Kuchinke L, Lux V. Caffeine improves left hemisphere processing of positive words. PLoS One. 2012;7(11):e48487.

43. Lorist MM, Snel J. Caffeine effects on perceptual and motor processes. Electroencephalogr Clin Neurophysiol. 1997;102(5):401-13.

44. Ruijter J, de Ruiter MB, Snel J, Lorist MM. The influence of caffeine on spatial-selective attention: an event-related potential study. Clin Neurophysiol. 2000;111(12):2223-33.

45. Giesbrecht T, Rycroft JA, Rowson MJ, De Bruin EA. The combination of L-theanine and caffeine improves cognitive performance and increases subjective alertness. Nutr Neurosci. 2010;13(6):283-90.

46. Roussinov KS, Yonkov DI. Cholinergic mechanisms in the learning and memory facilitating effect of caffeine. Acta Physiol Pharmacol Bulg. 1976;2(3):61-8.

47. Persuh M, Genzer B, Melara RD. Iconic memory requires attention. Frontiers in Human Neuroscience. 2012;6:126.

48. Bradley C, Pearson J. The sensory components of high-capacity iconic memory and visual working memory. Front Psychol. 2012;3:355.

49. Gruber RP, Block RA. Effects of caffeine on prospective duration judgements of various intervals depend on task difficulty. Human Psychopharmacol. 2005;20(4):275-85.

50. Smith A, Kendrick A, Maben A, Salmon J. Effects of breakfast and caffeine on cognitive performance, mood and cardiovascular functioning. Appetite. 1994;22(1):39-55

51. Valladares Lorraine Cl, Bedford A. Effects of caffeine on cognitive tasks. 2009 .

52. Gajewski PD, Stoerig P, Falkenstein M. ERP_Correlates of response selection in a response conflict paradigm. Brain Res. 2008;1189:127-34.

53. Serra-Grabulosa JM, Adan A, Falcón C, Bargalló N. Glucose and caffeine effects on sustained attention: an exploratory fMRI study. Hum Psychopharmacol Clin Exp. 2010;25(7-8):543-52.

54. Klaassen EB, de Groot RH, Evers EA, Snel J, Veerman EC, Ligtenberg AJ, et al. The effect of caffeine on working memory load-related brain activation in middle-aged males. Neuropharmacology. 2013;64:160-7.

55. Smillie LD, Gökçen E. Caffeine enhances working memory for extraverts. Biol Psychol. 2010;85(3):496-8.

56. Nehlig A. Is caffeine a cognitive enhancer? J Alzheimers Dis. 2010;20 Suppl 1:585-94.

\section{Submit your manuscript to a SpringerOpen ${ }^{\circ}$ journal and benefit from:}

- Convenient online submission

- Rigorous peer review

- Open access: articles freely available online

- High visibility within the field

- Retaining the copyright to your article

Submit your next manuscript at $\gg$ springeropen.com 